\title{
Estrogen potentiates treatment with T-cell receptor protein of female mice with experimental encephalomyelitis
}

\author{
Halina Offner,${ }^{1,2}$ Kirsten Adlard, ${ }^{1}$ Alex Zamora, ${ }^{1}$ and Arthur A. Vandenbark ${ }^{1,2,3,4}$ \\ ${ }^{1}$ Neuroimmunology Research, Veterans Affairs Medical Center, Portland, Oregon, USA \\ ${ }^{2}$ Department of Neurology, \\ ${ }^{3}$ Department of Molecular Microbiology and Immunology, and \\ ${ }^{4}$ Tykeson Multiple Sclerosis Research Laboratory, Oregon Health Sciences University, Portland, Oregon, USA \\ Address correspondence to: Halina Offner, Neuroimmunology Research, R\&D-31, Veterans Affairs Medical Center, \\ 3710 SW US Veterans' Hospital Road, Portland, Oregon 97201, USA. Phone: (503) 721-7893; Fax: (503) 721-7975; \\ E-mail: offner.halina@portland.va.gov. \\ Received for publication December 21, 1999, and accepted in revised form March 28, 2000.
}

Transgenic mice expressing the BV8S2 chain, which is specific for the myelin basic protein determinant Ac1-11, possess a naturally induced set of regulatory T cells directed against BV8S2. Further activation of anti-BV8S2 $\mathrm{T}$ cells in male mice with recombinant BV8S2 protein can inhibit IFN- $\gamma$ release by Ac1-11-specific $\mathrm{T}$ cells through a cytokine-driven mechanism and prevent induction of experimental autoimmune encephalomyelitis (EAE). In contrast, naive female mice possess fewer anti-BV8S2-reactive T cells, and treatment with BV8S2 delayed but did not prevent EAE. We here demonstrate that combining T-cell receptor (TCR) vaccination with supplemental estrus doses of estrogen potentiated IL-10 production by anti-BV8S2-reactive T cells and induced Ac1-11-specific T cells to produce IL-10 and TGF- $\beta$. This combined treatment resulted in full protection against EAE, which was not observed with either therapy alone. These findings imply that supplemental estrogen can enhance the efficacy of TCR-based immunotherapy for autoimmune diseases that predominate in females.

J. Clin. Invest. 105:1465-1472 (2000).

\section{Introduction}

Autoimmune diseases such as multiple sclerosis (MS), rheumatoid arthritis (RA), and Grave's disease preferentially affect women (1) and likely involve an oligoclonal expansion of autopathogenic Th1 cells directed at tissue-specific antigens (2). In general, women have a stronger immune response than men (3), perhaps contributing not only to a more effective immune surveillance and increased longevity, but also to a propensity for developing autoimmune diseases. Gender differences in the immune response and susceptibility to autoimmune diseases usually become apparent after sexual maturity (4). Sex hormones may contribute to susceptibility or resistance by influencing the development and function of pathogenic T cells, but conceivably, these hormones could also affect regulatory $\mathrm{T}$ cells that modify the course of disease.

Increased levels of sex hormones produced during pregnancy have been associated with clinical remissions in MS and RA patients, whereas reduced levels postpartum lead to an increased number of exacerbations (5-7). Similarly, pregnant animals develop less severe signs of experimental autoimmune encephalomyelitis (EAE) (8, 9), and estrogen, administered at levels found during pregnancy (100-fold higher than basal levels), can suppress $\operatorname{EAE}(10,11)$. Conversely, castration of female mice accelerates the onset of EAE (11). These observations suggest that whereas endogenous estrous and diestrous levels of estrogen may exert a limited inhibitory effect, high- er levels of supplemental estrogen are needed to suppress development of inflammatory Th1 responses (12).

Estrogen receptors (ER) have been demonstrated on human blood mononuclear cells, splenic and thymic cells (13), as well as HLA-DR negative human peripheral and thymic T cells (14), with some further indication that, within human T-cell subtypes ER expression might be limited to $\mathrm{CD}^{+}$cells $(15,16)$. However, estrogen has been shown to directly influence the cytokine secretion profile of human $\mathrm{CD}^{+} \mathrm{T}$-cell clones $(17,18)$, strongly implicating functional $\mathrm{ER}$, and we recently demonstrated ER $\alpha$ message in purified $\mathrm{CD}^{+} \mathrm{T}$ cells from mouse spleen (19). Moreover, Benten et al. (20) described a novel estradiol signaling pathway, present in both $\mathrm{CD}^{+}$and $\mathrm{CD}^{+} \mathrm{T}$ cells, which was mediated through plasma membrane receptors rather than the classical nuclear estrogen receptors. Taken together, these findings provide strong evidence that estrogen can bind to and regulate $\mathrm{CD}^{+} \mathrm{T}$ cells, thus allowing the possibility that estrogen might dampen inflammation either by directly inhibiting or deviating Th1 cells or by promoting development of regulatory Th2 (21) or $\mathrm{CD}^{+}(16)$ cells.

EAE is an inflammatory demyelinating disease of the central nervous system (CNS) that is induced by immunization of susceptible mice with myelin proteins or peptides in complete Freund's adjuvant (CFA) (22-25). Autoreactive $\mathrm{CD}^{+}$Th1 cells home specifically to the CNS and initiate the accumulation of inflammatory mononuclear cells, resulting in demyelination and clin- 
ical disease (26). As in MS, female mice develop more severe EAE than male mice $(27,28)$. We developed a new EAE treatment model using recombinant BV8S2 proteins to induce regulatory $T$ cells in male transgenic mice on the B10.PL background expressing the $\beta$ chain of the T-cell receptor (TCR) for myelin basic protein (MBP) Ac1-11 (29). T cells in unprimed mice proliferated vigorously to Ac1-11, but produced low levels of IFN- $\gamma$ and IL10 , indicating that these were naive effector precursor cells. The enhanced T-cell response to Ac1-11 encoded by the transgene induced a cognate $\mathrm{T}$-cell response to the TCR BV8S2 protein expressed by the MBP-specific T cells, suggesting natural priming in vivo. Induction of EAE by immunization with MBP-Ac1-11/CFA prompted MBP-specific T cells to greatly increase production of IFN- $\gamma$, provoking a concomitant increase of cytokine secretion by TCR-specific T cells. However, the mice developed relapsing EAE, indicating that the naturally induced anti-TCR T cells were not sufficient to inhibit disease. Vaccination with BV8S2 protein in incomplete Freund's adjuvant (IFA) before EAE induction reduced incidence and severity of disease and stimulated TCRspecific T cells to secrete elevated levels of both IFN- $\gamma$ and IL-10 (29) These regulatory T cells expressed the same Tg BV8S2 chain and the same AV2S3 chain as the encephalitogenic T cells, differing only in the AV-CDR3 junctional region (30), and could inhibit activation and transfer of EAE after coculture with the MBP-Ac111-specific T cells (29) through release of IL-10, IL-4, and IFN- $\gamma$, but not TGF- $\beta$ (31). These data demonstrate that immune regulation in this model occurs through a nondeletional cytokine-driven suppressive mechanism involving TCR-specific $\mathrm{T}$ cells (32). We now show that, in contrast to males, female littermate mice developed more severe EAE and were only transiently protected from EAE after vaccination with BV8S2 protein. To clarify these gender differences in susceptibility and treatment in EAE, we further evaluated the combined effects of TCR vaccination and estrogen on both pathogenic and regulatory $\mathrm{T}$ cells.

\section{Methods}

Mice. $\operatorname{Tg}$ mice bearing the functionally rearranged BV8S2 gene specific for MBP-Ac1-11 on the B10.PL background were kindly provided by Joan Goverman (Seattle, Washington, USA). Male Tg mice were bred with B10.PL females, and the offspring were tested for

\section{Table 1}

Serum concentrations of $17 \beta$-estradiol maintained in mice by implanted hormone pellets and physiological equivalents

\begin{tabular}{lll} 
Pellet $(\mathrm{mg})$ & $17 \beta$-estradiol $(\mathrm{pg} / \mathrm{mL})$ & Physiological equivalent \\
15 & $9,000-10,000$ & Pregnancy $(5,000-10,000 \mathrm{pg} / \mathrm{mL})$ \\
5 & $3,000-4,000$ & \\
2.5 & $1,500-2,000$ & \\
1.5 & $800-1,000$ & \\
0.36 & $150-200$ & Estrus $(100-200 \mathrm{pg} / \mathrm{mL})$ \\
0.10 & $25-50$ & Diestrus $(20-30 \mathrm{pg} / \mathrm{mL})$ \\
0.025 & $5-10$ & \\
\hline
\end{tabular}

expression of the transgene by FACS analysis of blood cells stained for BV8S2 as described previously (33). Approximately half of each litter expressed the BV8S2 transgene, with approximately half of these transgenic littermates of each sex. For some experiments, mice expressing the BV8S2 transgene were compared with littermates that did not express the transgene. The colony was housed and cared for at the Animal Resource Facility (Veterans Affairs Medical Center, Portland, Oregon, USA) according to institutional guidelines.

Antigens. N-acetylated MBP-1-11 peptide (Ac-ASQKRPSQRSK) was synthesized using solid-phase techniques and was purified by HPLC at the Beckman Institute, Stanford University (Stanford, California, USA). Glutathione S-transferase (GST) and GST-BV8S2 proteins were expressed and purified as described previously (34). The GST-BV8S2 fusion protein contains the complete $\mathrm{BV}, \mathrm{BD}$, and $\mathrm{BJ}$ regions, and the first 19 residues of the $B C$ region from the TCR of an encephalitogenic rat Tcell clone fused to the COOH-terminal end of GST. To control for the GST-BV8S2 protein, the GST protein was produced and purified using the same expression system. The GST protein was included as a control in all tissue culture experiments using the GST-BV8S2 protein.

Induction of active EAE and protection with BV8S2 protein or estrogen therapy. EAE was induced in $\mathrm{Tg}$ male or female mice by injecting $400 \mu \mathrm{g}$ MBP-Ac1-11/CFA containing $200 \mu \mathrm{g}$ Mycobacterium tuberculosis subcutaneously over four sites on the flank. For TCR protection experiments, mice were injected with $12.5 \mu \mathrm{g}$ recombinant rat BV8S2 protein/IFA (experimental), or saline/IFA, or GST/IFA (sham controls), intraperitoneally, on days -7 and +3 relative to injection of the MBP-Ac1-11, according to the protocol developed by Kumar and Sercarz (35). In an alternative protocol, mice were given the initial two injections and then boosted weekly with $12.5 \mu \mathrm{g}$ BV8S2 protein or saline given subcutaneously. Groups of male and female mice that were treated with TCR protein (Figure 1) were littermates, although data from the male mice have been reported previously (29). For estrogen hormone therapy or combined estrogen plus TCR therapy, $3-\mathrm{mm}$ pellets containing varying amounts of $17 \beta$-estradiol or estriol (Innovative Research of America, Sarasota, Florida, USA) were implanted subcutaneously on the animal's back 7 days before induction of EAE. Control mice were sham operated but received no pellet. The estrogen pellets provide continuous controlled release of a constant level of hormone over a period of 60 days. The concentration of $17 \beta$-estradiol in pellets used in our experiments and the expected serum concentration of secreted hormone maintained in the mice are listed in Table 1, along with the established range of physiological serum hormone levels during the estrus cycle and pregnancy (36). Serum concentrations of estrogen monitored before and during the course of EAE in representative control and implanted mice consistently fell within the expected ranges.

Mice were assessed daily for clinical signs of EAE according to the following scale: 0 , no signs; 1 , limp tail; 
Figure 1

Protection of male but not female BV8S2 Tg mice with BV8S2 protein. Littermate males ( $\mathbf{a}$ and $\mathbf{b}$ ) or females (c and d) were treated with saline/IFA or GST/IFA (controls) or $12.5 \mu \mathrm{g}$ BV8S2 protein/IFA on days -7 and +3 relative to challenge with MBP-Ac1-11 peptide/CFA + pertussigen to induce EAE, with (b and $\mathbf{d}$ ) or without (a and $\mathbf{c}$ ) weekly boosting with $12.5 \mu \mathrm{g}$ BV8S2 protein injected subcutaneously in saline. Note nearly complete protection against EAE in boosted males and delayed onset but eventual development of severe EAE in boosted females. Data from male mice are taken from ref. 19 . a

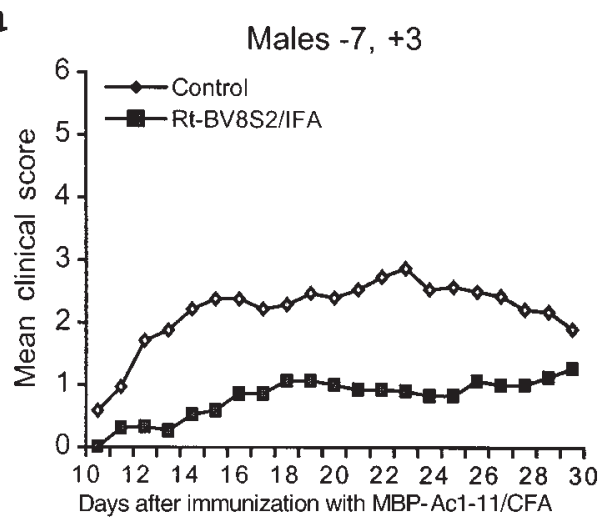

c

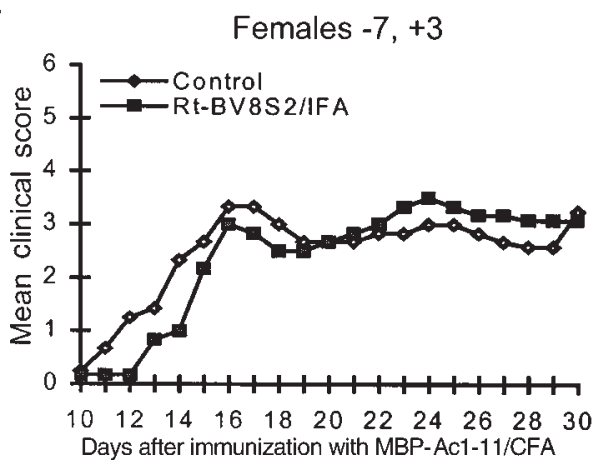

b

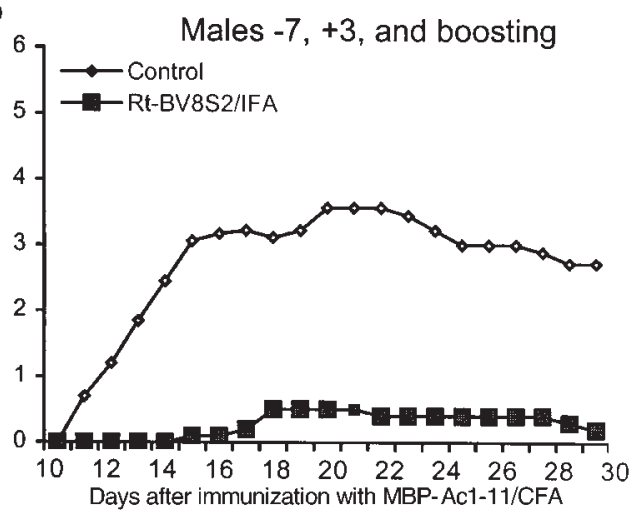

d

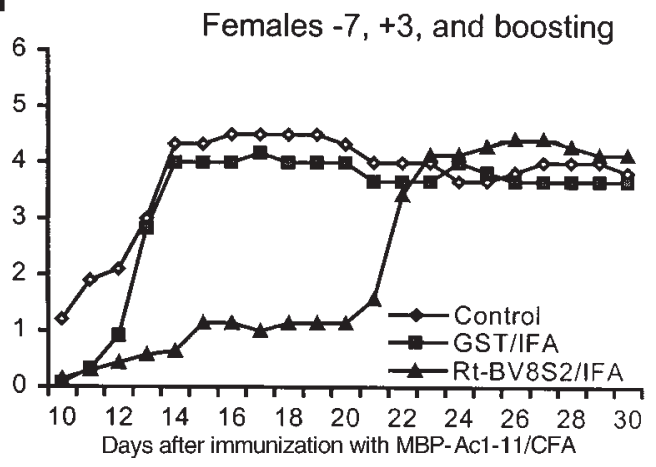

2, moderate hind-limb weakness (waddling gait); 3 , moderately severe hind-limb weakness; 4 , severe hindlimb weakness; 5 , paraplegia; 6 , quadriplegia, moribund condition. The cumulative disease index (CDI) was determined for each mouse by summing the daily clinical scores, and the mean CDI plus or minus SEM was calculated for the control and experimental groups. The mean clinical score (MCS) was calculated for each mouse by dividing the CDI by the duration (days) of disease, and the mean plus or minus SEM was calculated for the control and experimental groups.

Proliferation assay. Spleens (SPL) were removed surgical$l y$, and single-cell suspensions were prepared. Proliferative responses of $\mathrm{T}$ cells were determined in 96-well microtiter plates by incubating $4 \times 10^{5}$ spleen cells plus antigen at an optimal concentration of $20 \mu \mathrm{g} / \mathrm{well}$. Cultures were incubated for 72 hours at $37^{\circ} \mathrm{C}$ and $7 \% \mathrm{CO}_{2}$, the last 18 hours in the presence of $0.5 \mu \mathrm{Ci}^{3} \mathrm{H}$-thymidine. Cells were harvested onto glass fiber filters, and thymidine uptake was determined by liquid scintillation. Mean $\mathrm{cpm} \pm$ SEM were calculated from triplicate wells. The stimulation index (SI) was obtained by dividing cpm from antigen-stimulated wells by cpm from wells with no antigen. SI in cultures stimulated with GST alone was subtracted from the SI induced with GST-BV8S2 protein.

Measurement of cytokine secretion. Spleen cells were suspended at $4 \times 10^{6}$ cells $/ \mathrm{mL}$ in stimulation medium with and without specific antigens. Cell culture supernatants were recovered at 72 hours and frozen at $-70^{\circ} \mathrm{C}$ until needed for the cytokine assay. Measurement of cytokines was performed by ELISA developed in our laboratory (19), using cytokine-specific capture and detection antibodies (PharMingen, San Diego, California, USA). Capture antibodies for IFN- $\gamma$, IL-10, and TGF- $\beta$ were diluted to $2 \mu \mathrm{g} / \mathrm{mL}$ in bicarbonate coating buffer (0.1 $\mathrm{M} \mathrm{NaHCO}_{3}, \mathrm{pH}$ 8.2). Standard curves for each assay were generated using recombinant mouse cytokines (PharMingen), and the concentration of cytokines in the cell supernatants was determined by interpolation from the appropriate standard curve.

Assessment of antibody responses. Antibody reactivity to MBP-Ac1-11 peptide and GST-BV8S2 protein was determined by indirect ELISA as described previously (37). Briefly, mouse antisera from treated and control Tg mice

\section{Table 2}

Protection of male but not female BV8S2 Tg mice with BV8S2 protein

\begin{tabular}{|c|c|c|c|c|c|c|}
\hline Group & Figure & $\begin{array}{l}\text { Treatment } \\
\text { group }\end{array}$ & Incidence & $\begin{array}{l}\text { Day of } \\
\text { onset }\end{array}$ & CDI & \\
\hline Males & $1 \mathrm{a}$ & $\begin{array}{l}\text { Controls } \\
\text { BV8S2 }\end{array}$ & $\begin{array}{l}13 / 16 \\
6 / 16^{A}\end{array}$ & $\begin{array}{l}15 \pm 1 \\
14 \pm 1\end{array}$ & $\begin{array}{l}49 \pm 10 \\
17 \pm 7^{A}\end{array}$ & \\
\hline Males & $1 b$ & $\begin{array}{l}\text { Controls } \\
\text { BV8S2, B }\end{array}$ & $\begin{array}{c}10 / 10 \\
1 / 9^{C}\end{array}$ & $\begin{array}{c}13 \pm 1 \\
15\end{array}$ & $\begin{aligned} 63 & \pm 9 \\
7 & \pm 7 c\end{aligned}$ & \\
\hline Females & $1 c$ & $\begin{array}{l}\text { Controls } \\
\text { BV8S2 }\end{array}$ & $\begin{array}{l}5 / 5 \\
6 / 6\end{array}$ & $\begin{array}{l}15 \pm 4 \\
13 \pm 1\end{array}$ & $\begin{array}{l}75 \pm 12 \\
82 \pm 23\end{array}$ & \\
\hline & & & & & Day 1-21 & Day $22-30$ \\
\hline Females & $1 d$ & $\begin{array}{l}\text { Controls } \\
\text { GST } \\
\text { BV8S2,B }\end{array}$ & $\begin{array}{l}6 / 6 \\
6 / 6 \\
7 / 7\end{array}$ & $\begin{array}{l}11 \pm 1 \\
12 \pm 1 \\
19 \pm 5^{B}\end{array}$ & $\begin{array}{l}43 \pm 5 \\
36 \pm 4 \\
10 \pm 7 \mathrm{~B}\end{array}$ & $\begin{array}{l}35 \pm 5 \\
34 \pm 3 \\
37 \pm 3\end{array}$ \\
\hline
\end{tabular}

$\mathrm{CDI}$ is sum of daily scores; $12.5 \mu \mathrm{g}$ BV8S2/IFA on days -7 and +3 . ${ }^{A} P<0.05$. ${ }^{B} P<0.01 .{ }^{C} P<0.001$. B, weekly boosts with BV8S2/IFA. 


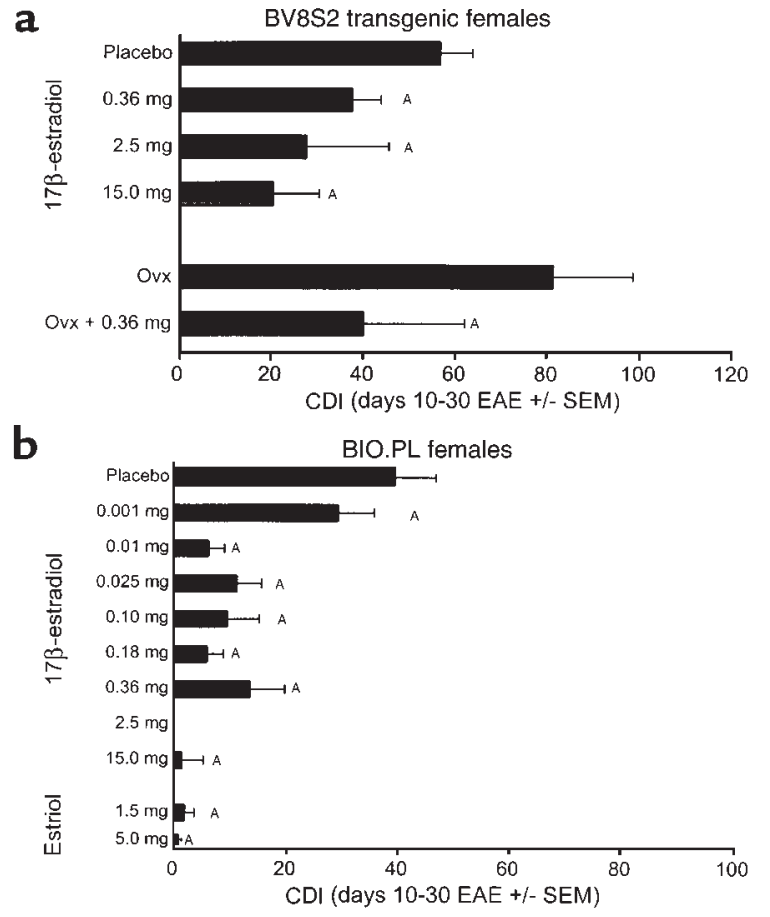

Figure 2

Inhibitory effects on EAE of $17 \beta$-estradiol and estriol on intact and ovariectomized female mice. Hormone pellets releasing controlled levels of estrogen (see Table 1 for the range of serum concentrations maintained by various pellet sizes) were surgically implanted 7 days before induction of EAE with MBP-Ac1-11 peptide/CFA + pertussigen. (a) Intact and ovariectomized $\mathrm{Tg}$ females, as indicated. (b) Intact (nonovariectomized) B10.PL female littermates. Note increased severity of EAE in ovariectomized versus intact $\mathrm{Tg}$ females, in intact $\mathrm{Tg}$ versus B10.PL females, and dose-dependent inhibition of EAE in both $\mathrm{Tg}$ and B10.PL females, with reduced sensitivity in $\mathrm{Tg}$ females. A total of 30 sham-operated and 81 experimental B10.PL female mice, and 36 sham-operated and 56 experimental $\mathrm{Tg}$ female mice were used in a total of nine combined experiments, with total group sizes ranging from five to 33 mice. ASignificant difference between control and experimental $(P<0.05)$. Ovx, ovariectomized.

with EAE were incubated in antigen-coated wells, and bound antibody was detected spectrophotometrically with peroxidase-labeled rabbit anti-mouse antibody and $o$-phenylene-diamine as a substrate. Differences between groups were determined using Student's $t$ test.

Ovariectomy. The ovaries were removed by making two bilateral incisions $(5 \mathrm{~mm})$ halfway between the base of the tail and the middle of the back, followed by small incisions $(2.5 \mathrm{~mm})$ through the peritoneal wall. The ovaries were pulled through the incisions by grasping the periovarian fat, the blood vessels were ligated, and the ovaries were removed. The incision was closed by surgical skin clips. The animals were allowed to recover for at least 1 week before initiation of experiments.

Androgen and estrogen detection. Mice were bled by cardiac puncture and the blood was allowed to clot at $4{ }^{\circ} \mathrm{C}$ overnight. The samples were centrifuged, and the sera were collected and stored at $-80^{\circ} \mathrm{C}$ until hormone analy- sis was performed. Serum levels of estrogen were determined by radioimmunoassay (RIA) after Sephadex LH20 column chromatography, as described previously (38). All samples were analyzed in a single assay.

\section{Results}

Gender difference in treatment of EAE with BV8S2 protein. We compared response to vaccination with BV8S2 protein in male versus female $\mathrm{Tg}$ mouse littermates, using two different protocols. As is shown in Figure 1a and quantified in Table 2, males injected intraperitoneally with BV8S2 protein/IFA on days -7 and +3 relative to EAE induction were significantly protected from EAE, with lower incidence and CDI than sham-treated males (data reproduced for males from ref. 29). In contrast, females vaccinated using the same protocol were not protected from EAE (Figure 1c and Table 2). As is illustrated in Figure $1 \mathrm{~b}$ and Table 2 , the protective effect in males could be enhanced by boosting weekly with additional subcutaneous injections of BV8S2 protein. These boosting injections had an early effect on littermate females as well, producing a significant delay in onset of clinical disease (Figure $1 \mathrm{~d}$ and Table 2). However, this temporary suppression of clinical disease was lost abruptly (Figure 1d), and there was no significant amelioration of subsequent disease assessed during days 18-30 (Table 2).

Effects of estrogen on EAE. The effects of sex hormones, including $17 \beta$-estradiol and estriol, were evaluated on the clinical course of EAE by hormone depletion or addition experiments. As is shown in Figure 2a, female Tg mice unable to produce detectable levels of estrogen $(<1$ $\mathrm{pg} / \mathrm{mL}$ ) or other sex hormones after ovariectomy developed significantly more severe EAE than sham-ovariectomized females $(\mathrm{CDI}=81$ vs. $56 ; P<0.001)$. These data demonstrate that even basal levels of ovarian factors, possibly including estrogen, provide some regulation of EAE. On the other hand, treatment of sham- or nonovariectomized females with $17 \beta$-estradiol pellets produced a dose-dependent inhibition of EAE in both Tg females (Figure 2a) and B10.PL littermate females (Figure 2b). Notably, added estrogen had a less pronounced effect on the $\mathrm{Tg}$ versus non-Tg females. In B10.PL females, essentially complete inhibition of EAE was produced with 15$\mathrm{mg}$ pellets secreting pregnancy levels of $17 \beta$-estradiol (9,000-10,000 $\mathrm{pg} / \mathrm{mL}$ serum) over a 60 -day period or with 2.5 -mg pellets $(1,500-2,000 \mathrm{pg} / \mathrm{mL}$ serum), and substantial inhibition was produced over a wide range of estrogen concentrations from estrus $(0.36-\mathrm{mg}$ pellets secreting $150-200 \mathrm{pg} / \mathrm{mL}$ serum) to diestrus levels ( 0.10 -mg pellets secreting $25-50 \mathrm{pg} / \mathrm{mL}$ serum, Figure $2 \mathrm{~b}$ ). By comparison, in Tg females, pregnancy levels of hormone (15-mg pellets) produced a marked but incomplete inhibition of EAE, with estrus levels (0.36-mg pellets) producing only moderate inhibition (Figure 2a). Estriol, which is elevated only during pregnancy, had an inhibitory effect on EAE in B10.PL females equivalent to 17 $\beta$-estradiol (Figure $2 \mathrm{~b}$ ). The partial resistance to estrogen therapy in $\mathrm{Tg}$ females may be due to the higher native frequency of Ac111-specific $T$ cells afforded by the transgene (29), which 


\section{Figure 3}

The combination of BV8S2 vaccination plus estrus levels (0.36-mg pellets delivering $150-200 \mathrm{pg}$ hormone over 60 days) of $17 \beta$-estradiol provides almost complete protection against EAE in intact $\mathrm{Tg}$ females. Daily clinical severity of EAE in mice treated with either or both agents.

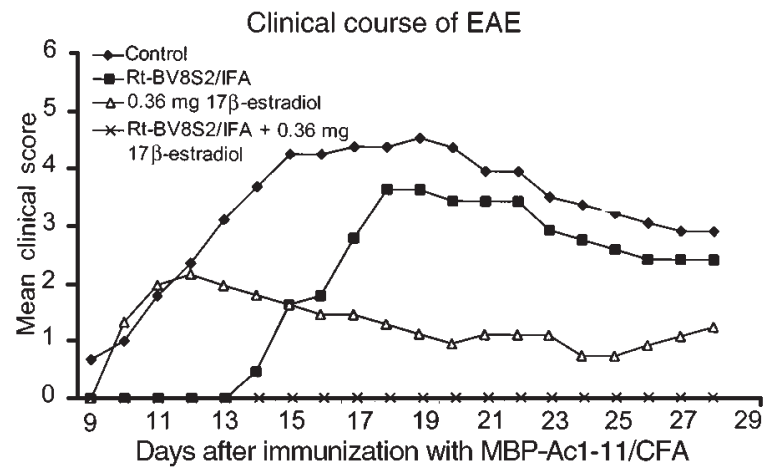

splenic T-cell responses to Ac1-11 peptide were characterized by moderate proliferation and production of TGF- $\beta$ and essentially absent secretion of IL-10 (Figure $4 \mathrm{~b})$. Secretion of IFN- $\gamma$ in response to Ac1-11 peptide was modest, reflecting preferential migration of inflammatory $\mathrm{T}$ cells to draining lymph nodes and the CNS as observed previously (29). Treatment with either BV8S2 protein or estrogen alone reduced proliferation and marginally affected cytokine responses to Ac1-11. However, combined treatment with both BV8S2 protein and estrogen markedly reduced proliferation and dramatically enhanced production of IL-10 and TGF- $\beta$, but not IFN$\gamma$ in response to Ac1-11 peptide (Figure $4 \mathrm{~b}$ ). In contrast, splenic proliferation and IL-10 responses to BV8S2 protein were enhanced by both treatments individually and further potentiated with combination therapy, with no significant effects of treatment on IFN- $\gamma$ and TGF- $\beta$ secretion (Figure 4c). Additionally, combination therapy reduced circulating levels of Ac1-11-specific IgG2a antibody associated with Th1 response, with no effect on IgG1 response (Figure 4d).

\section{Discussion}

The results presented above demonstrate, we believe for the first time, the powerful effects of combined TCR plus estrogen therapy on EAE in $\mathrm{Tg}$ female mice that are only partially responsive to either treatment alone. Concomitant administration of TCR protein and supplemental estrogen not only potentiated IL-10 production by regulatory TCR-reactive $\mathrm{T}$ cells, but also induced robust secretion of IL-10 and TGF- $\beta$ by MBP-Ac1-

Estrogen skews response to Ac1-11 and potentiates respons $B V 8 S 2$ protein. To investigate the mechanism(s) involved in individual and combined therapies, we evaluated proliferation and cytokine responses of immune $T$ cells from naive and treated mice. As is shown in Figure 4a, BV8S2 naive Tg males and females had equivalent proliferation responses to Ac1-11 peptide, purified protein derivative (PPD), and ConA, but naive $\mathrm{Tg}$ females had a strikingly reduced reactivity to the BV8S2 protein. This finding suggests that $\mathrm{Tg}$ females have a diminished native capacity to regulate an encephalitogenic response.

During development of EAE,

\section{Table 3}

Clinical parameters of individual and combination therapy in intact and ovariectomized Tg females

\begin{tabular}{|c|c|c|c|c|c|}
\hline Total & Incidence & Onset & Peak & Mortality & Average CDI (10-30) \\
\hline Control & $60 / 64$ & $11.8 \pm 1.1$ & $4.7 \pm 0.1$ & $12 / 49$ & $56.4 \pm 7.0$ \\
\hline BV8S2 & $45 / 49$ & $17.4 \pm 2.2^{\mathrm{A}}$ & $3.9 \pm 1.1^{\mathrm{A}}$ & $1 / 49$ & $32.0 \pm 13.2^{\mathrm{A}}$ \\
\hline $17 \beta$-estradiol & $25 / 33$ & $15.1 \pm 2.1^{\mathrm{A}}$ & $3.6 \pm 0.7^{\mathrm{A}}$ & $1 / 33$ & $37.3 \pm 6.2^{\mathrm{A}}$ \\
\hline BV8S2 + 17ß-estradiol & $3 / 16$ & $18.8 \pm 8.0^{\mathrm{A}}$ & $0.5 \pm 0.4^{\mathrm{A}}$ & $1 / 16$ & $3.1 \pm 4.0^{\mathrm{A}}$ \\
\hline Ovx & $27 / 27$ & $10.6 \pm 0.9$ & $5.3 \pm 0.7$ & $7 / 27$ & $81.2 \pm 17.3^{A, C}$ \\
\hline BV8S2 & $23 / 26$ & $18.0 \pm 1.9$ & $3.9 \pm 1.3$ & $4 / 26$ & $40.1 \pm 20.9^{\mathrm{B}}$ \\
\hline $17 \beta$-estradiol & $11 / 15$ & $13.6 \pm 1.5$ & $3.5 \pm 0.8$ & $4 / 15$ & $40.0 \pm 22.1^{B}$ \\
\hline BV8S2 + $17 \beta$-estradiol & $3 / 16$ & $20.8 \pm 6.0$ & $0.9 \pm 0.9$ & $0 / 16$ & $7.4 \pm 6.7^{\mathrm{A}, \mathrm{B}}$ \\
\hline
\end{tabular}

Data are combined from a total of 10 separate experiments. ASignificant difference between control and experimental $(P<0.0001)$. ${ }^{B}$ Significant difference between Ovx control and Ovx experimental $(P$ $<0.0001)$. ${ }^{C}$ Significant difference between Ovx and non-Ovx control $(P<0.001)$. Ovx, ovariectomized. 
11-specific T cells. This demonstration that supplemental estrogen given at estrus levels can enhance the efficacy of TCR-based therapy prompts us to speculate that estrogen might also augment other immunoregulatory strategies for human autoimmune diseases.

a

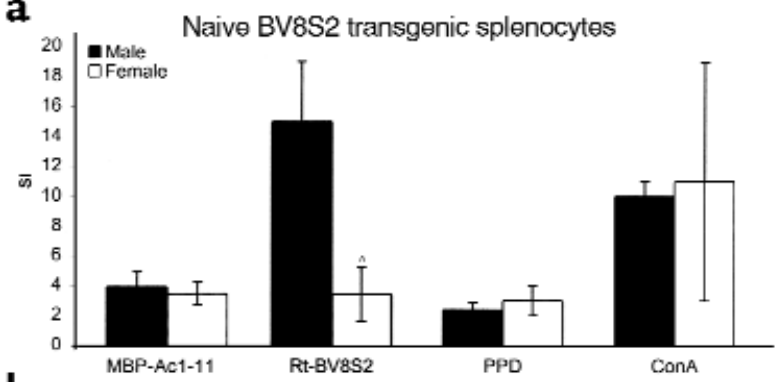

b

MBP-AC1-11 response in BV8S2 transgenic females
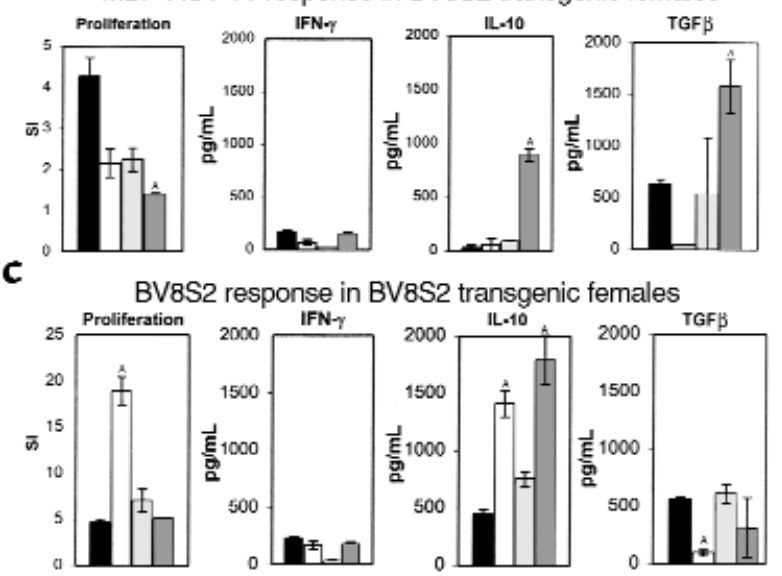

d

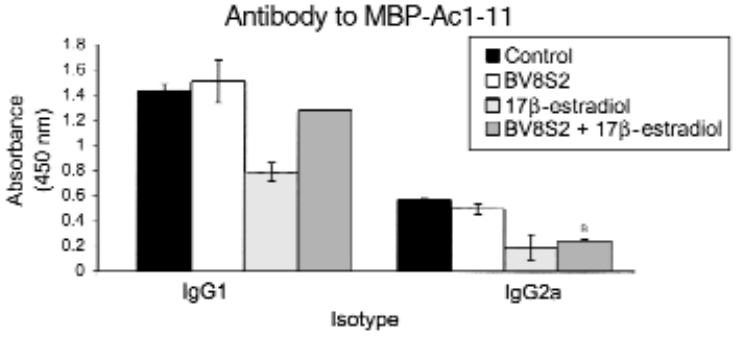

Figure 4

T-cell and antibody responses in treated and control $\mathrm{Tg}$ mice challenged to develop EAE. (a) Proliferation responses of lymph node cells to Ac1-11 and BV8S2 protein in naive male and female Tg mice. Note decreased female response to BV8S2 protein. (b) Proliferation and cytokine responses to Ac1-11 of splenocytes from control and treated $\mathrm{Tg}$ females sampled at the peak of EAE (day 15). Note striking increase in production of IL-10 and TGF- $\beta$ in mice treated with both BV8S2 protein and estrus levels of estrogen. (c) Proliferation and cytokine responses to BV8S2 protein of splenocytes from control and treated $\mathrm{Tg}$ females sampled at the peak of EAE (day 15). Note increased production of IL-10 in mice treated with BV8S2 protein, estrus levels of estrogen, or both agents. (d) Serum antibody responses to Ac1-11 in control and treated Tg females (day 29). Note decreased $\operatorname{lgG} 2 \mathrm{a}$ antibody in estrogen or combined treatment groups. (a) Composite data from 14 mice per group. (b, c, and d) Representative of two to four separate experiments. ASignificant difference between control and experimental $(P<0.0001)$; ${ }^{B}$ significant difference between control and experimental $(P<0.01)$.
It is apparent from these studies that the underlying mechanisms involved in TCR-based regulation and estrogen therapy are highly complementary. Vaccination with TCR protein preferentially induces Th2-like cells that inhibit Th1-cell activation and transfer of EAE by secretion of regulatory cytokines, including IL-10 and IL-4, but not TGF- $\beta(29,31)$. Estrogen given at estrus levels also enhanced IL-10 production by TCR-reactive T cells, even in the absence of additional TCR protein. In addition, estrogen alone inhibited proliferation of Ac1-11-specific T cells, but had little effect on cytokine production. However, the combination of both approaches had an additive effect on BV8S2 reactive cells that promoted the highest levels of IL-10, as well as a synergistic effect on MBP-Ac111 -specific $\mathrm{T}$ cells that triggered production of both IL-10 and TGF- $\beta$, but not IFN- $\gamma$. IL-10 has been shown to be a critical cytokine for regulating EAE in mice (39), and an important mechanism underlying our observations is that combined TCR plus estrogen therapy resulted in optimal IL-10 production by both TCR- and MBP-specific T cells.

It seems probable that the supplemental estrogen acted directly on both MBP-Ac1-11- and BV8S2-reactive $T$ cells to modify their function. In addition to our recent observation that $\mathrm{ER} \alpha$ is expressed on $\mathrm{CD} 4^{+}$ splenocytes from mice (19), Benten et al. (20) demonstrated that estradiol can bind to the plasma membrane of all $\mathrm{CD}^{+}$(as well as all $\mathrm{CD}^{+}$) T cells through receptors that are not the classical genomic ERs. Binding of estradiol stimulated $\mathrm{Ca}^{2+}$ influx through $\mathrm{Ca}^{2+}$ channels and release of $\mathrm{Ca}^{2+}$ from the endoplasmic reticulum, resulting in impaired signaling through the TCR. Thus, estrogen could conceivably act through either classical or nonclassical pathways to functionally modulate activation and cytokine profiles of both pathogenic and regulatory $\mathrm{CD} 4^{+} \mathrm{T}$ cells. The estrogenenhanced production of anti-inflammatory lymphokines by the TCR-reactive T cells might have provided the milieu needed to cause immune deviation of MBP-Ac1-11-specific T cells and antibodies, as has been suggested previously (40-42). Autopathogenic Tcell specificities that have been skewed to produce Th2 cytokines, including IL-4, IL-10, and TGF- $\beta$, have been associated with a nonencephalitogenic phenotype (43), except under one specific but unusual circumstance (44). Moreover, the local secretion of these inhibitory lymphokines by deviated or genetically transduced pathogenic $T$ cells could protect against EAE by suppression of bystander pathogenic T cells (45-48).

It is clear that basal levels of ovarian hormones exert a regulatory influence on $\mathrm{EAE}$, since ovariectomized $\mathrm{Tg}$ females with no detectable estrogen or progesterone developed significantly more severe disease than shamoperated females. Estrogen treatment profoundly inhibited EAE in B10.PL females, but had a less pronounced effect in $\mathrm{Tg}$ females, perhaps owing to the higher frequency of MBP-reactive T cells afforded by the Ac111 -reactive TCR $\beta$-chain transgene. Interestingly, treat- 
ment of ovariectomized Tg females with $17 \beta$-estradiol produced a comparable degree of EAE inhibition as in sham-operated Tg females (Figure 2), indicating that this or closely related estrogen analogues contributed to natural regulation in intact females. However, in both cases, inhibition of EAE was incomplete, connoting a limited estrogen effect and an estrogen-insensitive component of the encephalitogenic cascade in $\mathrm{Tg}$ females.

Similarly, treatment with BV8S2 protein was ultimately ineffective at controlling EAE in Tg females, although this therapy did cause a significant delay in disease onset. The eventual onset of full symptoms of EAE in TCRtreated female $\mathrm{Tg}$ mice likewise indicated incomplete regulation in the absence of supplemental estrogen. The essentially complete protection against EAE observed with combined therapy was obviously estrogen dependent and clearly involved highly compatible dynamic interactions. Based on the well-described effects of estrogen for forming ligand-activated nuclear transcription factors that function as upstream promoters of affected genes (49), we would speculate that supplemental estrogen could act directly through the classical genomic ER to upregulate IL-10 production by TCR-reactive T cells. The enhanced levels of IL-10 might then more efficiently skew responses of the MBP-Ac1-11-reactive T cells to produce additional IL-10 and TGF- $\beta$. Estrogen, estriol, and $17 \beta$ estradiol at pregnancy levels have all been shown to enhance IL-10 as well as IFN- $\gamma$, but not IL- 4 or TGF- $\beta$, secretion by $\mathrm{CD}^{+}{ }^{+}$proteolipid protein-specific (PLP-specific) T cells from MS and control patients $(17,18)$. In our study, $17 \beta$-estradiol alone did not significantly alter IL10 or TGF- $\beta$ production by MBP-Ac1-11-specific T cells when given at relatively low estrus level doses in the absence of TCR protein. The possible promoter effect of estrogen on IL-10 production by both TCR and MBPreactive $T$ cells is currently under investigation.

The profound protective effect of combined TCR vaccination and estrogen therapy observed in the current study has important implications for treatment of human autoimmune diseases. Many of these conditions preferentially affect women and probably involve tissue antigen-specific inflammatory $T$ cells that can be targeted by TCR vaccines. TCR-based immunotherapy has shown a possible clinical benefit in patients with MS (50) and RA (51), but the treatment affects only about half the patients, and clinical changes are, for the most part, moderate. Clinical trials using pregnancy levels of estriol to treat females with MS are in progress (R. Voskuhl, personal communication). However, supplemental estrogen or estriol alone also may not fully regulate pathogenic T cells in MS, even if given at pregnancy doses, because of enhanced resistance to regulation (52). Our data suggest that a much lower estrus dose of $17 \beta$-estradiol could have both a potentiating effect on regulatory TCR-reactive T cells and a synergistic effect on MBP-reactive T cells for producing anti-inflammatory cytokines when used in combination with TCR protein vaccination. Similarly, lower doses of estrogen may be highly compatible and complementary with other forms of immune therapy that are aimed at inducing immune deviation, including altered peptide ligands (53) and low-dose oral tolerance (54).

\section{Acknowledgments}

The authors wish to thank Eva Niehaus for assistance in preparing the manuscript. This work was supported by National Institutes of Health grants NS-23221, NS23444, and AI-42376, The National Multiple Sclerosis Society, the Nancy Davis Center Without Walls, and the U.S. Department of Veterans Affairs.

1. Homo-Delarche, F., et al. 1991. Sex steroids, glucocorticoids, stress and autoimmunity. J. Steroid Biochem. Mol. Biol. 40:619-637.

2. Hafler, D.A., Saadeh, M.G., Kuchroo, V.K., Milford, E., and Steinman, L. 1996. TCR usage in human and experimental demyelinating disease. Immunol. Today. 17:152-159.

3. Ansar-Ahmed, S., Penhale, W.J., and Talal, N. 1985. Sex hormones, immune responses and autoimmune diseases: mechanisms of sex hormone action. Am. J. Pathol. 121:531-551.

4. Birk, K., et al. 1990. The clinical course of multiple sclerosis during pregnancy and the puerperium. Arch. Neurol. 47:738-742.

5. Korn-Lubetzki, I., Kahana, E., Cooper, G., and Abramsky, O. 1984. Activity of multiple sclerosis during pregnancy and puerperium. Ann. Neurol. 16:229-231.

6. Confavreux, C., Huchinson, M., Hours, M.M., Corinovis-Tourniaire, P., and Moreau, T. 1998. Rate of pregnancy-related relapse in multiple sclerosis. Pregnancy in Multiple Sclerosis Group. N. Engl. J. Med. 339:285-291.

7. Ostensen, M., and Husby, G.A. 1983. A prospective clinical study of the effect of pregnancy on rheumatoid arthritis and ankylosing spondylitis. Arthritis Rheum. 26:1155-1159.

8. Evron, S., Brenner, T., and Abramsky, O. 1984. Suppressive effect of pregnancy on the development of experimental allergic encephalomyelitis in rabbits. Am. J. Reprod. Immunol. 5:109-113.

9. Mertin, L.A., and Rumjanek, V.M. 1985. Pregnancy and susceptibility of Lewis rats to experimental allergic encephalomyelitis. J. Neurol. Sci. 68:15-24.

10. Trooster, W.J., et al. 1993. Suppression of acute experimental allergic encephalomyelitis by the synthetic sex hormone 17-alpha-ethinylestradiol: an immunological study in the Lewis rat. Int. Arch. Allergy Immunol. 102:133-140.

11. Jansson, L., Olsson, T., and Holmdahl, R. 1994. Estrogen induces a potent suppression of experimental autoimmune encephalomyelitis and collagen-induced arthritis in mice. J. Neuroimmunol. 53:203-207.

12. Raghupathy, R. 1997. Th1-type immunity is incompatible with successful pregnancy. Immunol. Today. 18:478-482.

13. Danel, L., Souweine, G., Monier, J.C., and Saez, S. 1983. Specific estrogen binding sites in human lymphoid cells and thymic cells. J. Steroid Biochem. 18:559-563.

14. Cohen, J.H., Danel, L., Cordier, G., Saez, S., and Revillard, J.P. 1983. Sex steroid receptors in peripheral T cells: absence of androgen receptors and restriction of estrogen receptors to OKT8-positive cells. J. Immunol. 131:2767-2771.

15. Danel, L., et al. 1985. Distribution of androgen and estrogen receptors among lymphoid and haemopoietic cell lines. Leuk. Res. 9:1373-1378.

16. Stimson, W.H. 1988. Oestrogen and human T lymphocytes: presence of specific receptors in the T-suppressor/cytotoxic subset. Scand. J. Immunol. 28:345-350.

17. Gilmore, W., Weiner, L.P., and Correale, J. 1997. Effect of estradiol on cytokine secretion by proteolipid protein-specific $\mathrm{T}$ cell clones isolated from multiple sclerosis patients and normal control subjects. $J$. Immunol. 158:446-451.

18. Correale, J., Arias, M., and Gilmore, W. 1998. Steroid hormone regulation of cytokine secretion by proteolipid protein-specific CD4+ T cell clones isolated from multiple sclerosis patients and normal control subjects. J. Immunol. 161:3365-3374.

19. Bebo, B.F.J., Schuster, J.C., Vandenbark, A.A., and Offner, H. 1999. Androgens alter the cytokine profile and reduce encephalitogenicity of myelin-reactive T cells. J. Immunol. 162:35-40.

20. Benten, W.P.M., Lieberherr, M., Giese, G., and Wunderlich, F. 1998. Estradiol binding to cell surface raises cytosolic free calcium in T cells. FEBS Lett. 422:349-353.

21. Wegmann, T.G., Lin, H., Guilbert, L., and Mosmann, T.R. 1993. Bidirectional cytokine interactions in the maternal-fetal relationship: is successful pregnancy a TH2 phenomenon? Immunol. Today. 14:353-356.

22. Fritz, R.B., Chou, C.-H.J., and McFarlin, D.E. 1983. Induction of experimental allergic encephalomyelitis in PL/J and (SJL/JxPL/J)F1 mice by myelin basic protein and its peptides: localization of a second 
encephalitogenic determinant. J. Immunol. 130:191-194.

23. Fritz, R.B., Chou, C.-H.J., and McFarlin, D.E. 1983. Relapsing murine experimental allergic encephalomyelitis induced by myelin basic protein. J. Immunol. 130:1024-1026.

24. Trotter, J.L., Clark, H.B., Collins, K.G., Wegeschiede, C.L., and Scarpellini, J.D. 1987. Myelin proteolipid protein induces demyelinating disease in mice. J. Neurol. Sci. 79:173-183.

25. McRae, B.L., et al. 1992. Induction of active and adoptive relapsing experimental autoimmune encephalomyelitis (EAE) using an encephalitogenic epitope of proteolipid protein. J. Neuroimmunol. 38:229-240.

26. Miller, S.D., and Karpus, W.J. 1994. The immunopathogenesis and regulation of T-cell-mediated demyelinating diseases. Immunol. Today. 15:356-361.

27. Voskuhl, R.R., Pitchekian-Halabi, H., MacKenie-Graham, A., McFarland, H.F., and Raine, C.S. 1996. Gender differences in autoimmune demyelination in the mouse: implications for multiple sclerosis. Ann. Neurol. 39:724-733.

28. Bebo, B.F.J., Vandenbark, A.A., and Offner, H. 1996. Male SJL mice do not relapse after induction of EAE with PLP 139-151. J. Neurosci. Res. 45:680-689.

29. Offner, H., et al. 1998. Vaccination with BV8S2 protein amplifies TCR specific regulation and protection against experimental autoimmune encephalomyelitis in TCR BV8S2 transgenic mice. J. Immunol. 161:2178-2186.

30. Buenafe, A.C., Tsu, R.C., Bebo, B.F., Vandenbark, A.A., and Offner, H. 1997. Myelin basic protein-specific and TCR VB8.2-specific T-cell lines from TCR VB8.2 transgenic mice utilize the same Valpha and Vbeta genes: specificity associated with the Valpha CDR3-Jalpha region. J. Neurosci. Res. 47:489-499.

31. Adlard, K., et al. 2000. Immunoregulation of encephalitogenic MBPAc1-11-reactive T cells by CD4+ TCR-specific T cells involves IL-4, IL10 and IFN-gamma. Autoimmunity. In press.

32. Vandenbark, A.A., Hashim, G.A., and Offner, H. 1996. T cell receptor peptides in treatment of autoimmune disease: rationale and potential. J. Neurosci. Res. 43:391-402.

33. Goverman, J., et al. 1993. Transgenic mice that express a myelin basic protein-specific $\mathrm{T}$ cell receptor develop spontaneous autoimmunity. Cell. 72:551-560.

34. Vainiene, M., et al. 1996. Neonatal injection of Lewis rats with recombinant V $\beta 8.2$ induces $T$ cell but not $B$ cell tolerance and increased severity of experimental autoimmune encephalomyelitis. J. Neurosci. Res. 45:475-486.

35. Kumar, V., and Sercarz, E.E. 1993. The involvement of T cell receptor peptide-specific regulatory CD4+ $\mathrm{T}$ cells in recovery from antigeninduced autoimmune disease. J. Exp. Med. 178:909-916.

36. Foster, H.L., Small, J.D., and Fox, J.G. 1983. Normative biology, immunology and husbandry. Academic Press Inc. Orlando, Florida, USA. 138-158.

37. Hashim, G., et al. 1990. Antibodies specific for a V $\beta 8$ T cell receptor peptide suppress experimental autoimmune encephalomyelitis. $J$. Immunol. 144:4621-4627.

38. Roselli, C.E., Klosterman, S.A., and Fasasi, T.A. 1996. Sex differences in androgen responsiveness in the rat brain: regional differences in the induction of aromatase activity. Neuroendocrinology 64:139-145.

39. Bettelli, E., et al. 1998. IL-10 is critical in the regulation of autoimmune encephalomyelitis as demonstrated by studies of IL-10- and IL-4-deficient transgenic mice. J. Immunol. 161:3299-3306.

40. Mossman, T.R., and Coffman, R.L. 1989. Th1 and Th2 cells: different patterns of lymphokine secretion lead to different functional properties. Annu. Rev. Immunol. 7:145-173.

41. Fiorentino, D.F., et al. 1991. IL-10 acts on the antigen-presenting cell to inhibit cytokine production by Th1 cells. J. Immunol. 146:3444-3451

42. Hsieh, C.-S., Heimberger, A.B., Gold, J.S., O'Garra, A., and Murphy, K. 1992. Differential regulation of T helper phenotype development by IL-4 and IL-10 in an aB-transgenic system. Proc. Natl. Acad. Sci. USA. 89:6065-6069.

43. Kuchroo, V.K., et al. 1993. Cytokines and adhesion molecules contribute to the ability of myelin proteolipid protein-specific $\mathrm{T}$ cell clones to mediate experimental allergic encephalomyelitis. J. Immunol. 151:4371-4382.

44. Lafaille, J.J., et al. 1997. Myelin basic protein-specific T helper 2 (Th2) cells cause experimental autoimmune encephalomyelitis in immunodeficient hosts rather than protect them from the disease. J. Exp. Med. 186:307-312.

45. Kuchroo, V.K., et al. 1995. B7-1 and B7-2 costimulatory molecules activate differentially the Th1/Th2 developmental pathways: application to autoimmune disease therapy. Cell. 80:707-718.

46. Shaw, M.K., et al. 1997. Local delivery of interleukin 4 by retrovirustransduced $\mathrm{T}$ lymphocytes ameliorates experimental autoimmune encephalomyelitis. J. Exp. Med. 185:1711-1714.

47. Mathisen, P.M., Yu, M., Johnson, J.M., Drazba, J.A., and Tuohy, V.K. 1997. Treatment of experimental autoimmune encephalomyelitis with genetically modified memory T cells. J. Exp. Med. 186:159-164.

48. Chen, Y., Kuchroo, V.K., Inobe, J.I., Hafler, D.A., and Weiner, H.L. 1994. Regulatory $\mathrm{T}$ cell clones induced by oral tolerance: suppression of autoimmune encephalomyelitis. Science. 265:1237-1240.

49. Korach, K.S. 1994. Insights from the study of animals lacking functional estrogen receptor. Science. 266:1542-1547.

50. Vandenbark, A.A., et al. 1996. Treatment of multiple sclerosis with T cell receptor peptides: results of a double-blind pilot trial. Nat. Med. 2:1109-1115.

51. Moreland, L.W., et al. 1998. T cell receptor peptide vaccination in theumatoid arthritis: a placebo-controlled trial using a combination of Vbeta3, Vbeta14, and Vbeta17 peptides. Arthritis Rheum. 41:1919-1929.

52. Correale, J., et al. 1996. Defective post-thymic tolerance mechanisms during the chronic progressive stage of multiple sclerosis. Nat. Med. 2:1354-1360.

53. Evavold, B.D., Sloan-Lancaster, J., and Allen, P.M. 1993. Tickling the TCR: selective T-cell functions stimulated by altered peptide ligands. Immunol. Today. 14:602-609.

54. Weiner, H.L., et al. 1994. Oral tolerance: immunologic mechanisms and treatment of animal and human organ-specific autoimmune diseases by oral administration of autoantigens. Annu. Rev. Immunol. 12:809-837. 